\title{
Evaluation of the Prevalence of Different Treatment Failure Modes after Crown Lengthening Surgical Procedures
}

\author{
Amirreza Babaloo ${ }^{1}$, Mahdi Rahbar ${ }^{2}$, Shima Ghasemi ${ }^{3 *}$, Mohammad Taghi Chitsazi $^{4}$, Saman Abbasi ${ }^{5}$
}

1. Assistant Professor, Department of Periodontics, Faculty of Dentistry, Tabriz University of Medical Sciences, Iran 2. Post-graduate Student, Department of Operative and Esthetic Dentistry, Faculty of Dentistry, Tabriz University of Medical Science, Tabriz, Iran

3. Assistant Professor, Department of Prosthodontics, Faculty of Dentistry, Tabriz University of Medical Sciences, Iran

4. Professor, Department of Periodontics, Faculty of Dentistry, Tabriz University of Medical Sciences, Iran

5. Dentist, Private practice, Tabriz, Iran

\begin{abstract}
Introduction: Preservation of the health of periodontium is very important for the long-term success of restored teeth and a balance should always be created between the patients' esthetic requirements and the periodontal health. Failures of crown lengthening procedures are classified into early and late failures. The aim of this study was to evaluate the prevalence of early failures of crown leathering surgical procedures. Materials and methods: In this descriptive/cross-sectional study, 96 patients were selected from those referring to the Department of Periodontitis, Tabriz Faculty of Dentistry, who required crown lengthening procedures. The particulars of these patients were recorded in special forms and the reasons for the failure of surgical procedures were separately determined at 2- and 6week intervals. In addition, the frequencies of the reasons for failures were determined in percentages and absolute frequencies. Data were analyzed with descriptive statistics (frequencies and percentages) using SPSS 21. Statistical significance was set at $P<0.05$. Results: Evaluation of patients 6 weeks after surgery showed a failure rate of $14.5 \%$ for crown lengthening procedures in patients referring to the Department of Periodontics, Tabriz Faculty of Dentistry. The most common reasons for such early failures in the 6th week, in descending order, were a lack of sufficient keratinized gingiva around in tooth in question, fracture of the tooth structure after surgery, inadequate surgery (not creating a proper distance between the healthy margin and the crest) and the coronal returning of the gingival tissue on the tooth. A lack of sufficient keratinized gingiva around the tooth was the most frequent reason for the early failure of crown lengthening procedure at both study intervals. Conclusion: It can be concluded from the results of the present study that during the 6th postoperative week the crown lengthening procedures exhibited a $14.5 \%$ failure rate and a lack of sufficient keratinized gingiva around the tooth was the most frequent reason for early failures of such procedures.
\end{abstract}

Key words: Crown lengthening surgical procedures; treatment failure; keratinized gingiva;

\section{Corresponding author:}

Shima Ghasemi

Department of Prosthodontics, Faculty of Dentistry, Tabriz University of Medical Sciences, Tabriz, Iran Tel: +989143180309 E-mail: dr_shimaghasemi@yahoo.com

Receive date: 2016-05-05| Accept date: 2016-06-25| Publish date: 2016-07-28

DOI: 10.7575/aiac.abcmed.16.04.03.02

\section{A. I}




\section{Introduction}

Currently, periodontal treatments are considered an important component of procedures to meet the esthetic equipments of patients. In this context, maintaining the periodontal health is an important prerequisite for the long-term success of tooth restorations. Therefore, dentists have to achieve a balance between the patients' esthetic requirements and periodontal health (1-4).

A clinician faces 3 choices for the placement of restoration margin: supragingival, at the gingival margin level and subgingival. Placing restoration margins supragingivally facilitates impression taking, observation of hygienic instructions and identification of recurrent caries, and it results in the health of soft tissues (5-7). However, under some conditions, including teeth with extensive caries, fractured teeth, dentin hypersensitivity, inadequate length of the clinical crown and esthetic requirements, the restoration margins should be placed apical to the gingival margin. Various studies have shown that restorations with subgingival margins exert unfavorable effects on adjacent hard and soft tissues, especially when the restoration margin impinges on the biologic width. Such restorations are associated with gingival inflammation, loss of connective tissue attachment and bone loss (5-7).

Crown lengthening procedures are carried out to increase the crown retention during preparation of the tooth, facilitate the impression taking procedure and establish sufficient ferrule to adjust the gingival level of restorations for esthetic purposes $(8,9)$. It is important to carry out crown lengthening procedures in a manner to preserve the biologic width. The biologic width is the sum of the physiologic dimensions of junctional epithelium and connective tissue attachments. This width is relatively constant at almost $2 \mathrm{~mm}$ $( \pm 30 \%)(10)$. Based on current hypotheses, impingement on the biologic width by placing restoration margins in this area can result in gingival inflammation, pocket formation and loss of the alveolar bone $(11,12)$.

A tooth crown lengthening procedure involves removal of soft tissue or both the soft tissue and the alveolar bone. Removal of the soft tissue alone is recommended when sufficient attached gingiva is available and there is more than $3 \mathrm{~mm}$ of soft tissue available coronal to the bone crest. In cases in which sufficient attached gingiva is not available and there is less than $3 \mathrm{~mm}$ of keratinized soft tissue available, flap surgery is necessary in association with correction of the boney contour (13). With the emergence of successful dental implant treatments, it is necessary to accurately assess the value of crown lengthening procedures and the ease of restorative procedures versus removal of the tooth and its replacement with dental implants (13). In a general classification, failures associated with the above treatment are divided into early (before placing the restoration) and late or delayed (after restorative procedures) failures. Early failures include coronal returning of the gingival tissue on the tooth structure, absence of adequate keratinized gingiva around the tooth, presence of granulation tissue in the coronal areas of tooth structure and not creating an adequate distance between the bone crest and the tooth margin. If the interproximal bone is removed, the odds are high for the restoration of the interdental papilla and creation of an unaesthetic triangular space beneath the interdental contact area (14).

Late failures are mainly due to the impingement of the restoration on the biologic space. Although the mean size of the biologic width is $2 \mathrm{~mm}$, as introduced by Gargiula et al (10), various ranges of biologic width have been reported, which are specific for each patient. 
Studies have reported the size of the biologic width from 0.75 in some patients to $4.3 \mathrm{~mm}$ in some others (15), indicating that the biologic width should be evaluated separately and specifically in each patient so that it would be possible to determine whether there is a need for a biologic width of $2 \mathrm{~mm}$ to achieve harmony between the restoration and the gingival tissue in that patient or not. Ignoring this will result in inflammatory problems and destruction of the periodontal tissue. Considering what was discussed above about the importance of crown lengthening procedure in restorative procedures, this study was undertaken to determine the prevalence of early failures of crown lengthening procedures.

\section{Materials and Methods}

In this descriptive/cross-sectional study, 96 patients were selected from those referring to Tabriz Faculty of Dentistry, who needed crown lengthening procedures.

The inclusion criteria consisted of the need for a crown lengthening procedure and informed consent to participate in the study. Exclusion criteria consisted of systemic conditions, contraindications for surgical procedures and a treatment plan for fixed prosthodontic treatments for the subject. The oral hygiene was promoted using general instructions, including the use of toothbrushes and dental floss, and specific instructions to keep the surgical site clean, including use of interdental brush and local antiseptic agents such as chlorhexidine. O'Leary's plaque index was recorded before the surgical procedure and during the follow-up sessions, and patients with a plaque index of $>20$ were excluded from the study and received oral hygiene instructions once again. Informed consent forms were obtained from the patients after they received sufficient explanations about the study procedures. The surgical procedures were carried out by postgraduate students in the Department of Periodontics, using similar instruments.

The patients' particulars, possible reasons for the early failure of surgical treatments were recorded in checklists. The reasons for the failure of surgeries were separately recorded during the second and sixth weeks. The patients did not receive any other treatments on the teeth that had undergone surgeries during this period.

Data were analyzed with descriptive statics (frequencies and percentages) using SPSS 21. Statistical significance was defined at $\mathrm{P}<0.05$.

\section{Results}

The present study was carried out on 96 patients referring to the Department of Periodontics, Tabriz Faculty of Dentistry, who were candidates for crown lengthening procedures in 2015; $59.3 \%$ (57 subjects) and $40.7 \%$ (39 subjects) of the patients were female and male, respectively. In general, of all the subjects evaluated, 14 subjects (14.5\%) exhibited early failure after surgery and 82 subjects (85.5\%) did not exhibit early failures.

Evaluation of the patients two week after surgery showed that 13 patients (11.5\%) of 96 patients under study had early failure for the following reasons: 7 cases (54\%) due to the absence of adequate keratinized gingiva around the tooth in question, 3 cases $(23 \%)$ due to the presence of granulation tissue around the tooth, 1 case $(8 \%)$ due to the fracture of the tooth structure and 2 cases (15\%) due to inadequate surgery (not creating a proper distance between the healthy margin and the crest). Evaluation of the patients 6 weeks after the crown lengthening procedures showed that 14 cases of 96 cases had experienced failure due to the following reasons: 2 cases (14\%) due to the coronal returning of the gingival tissue on the tooth structure, 7 cases (50\%) due to the absence of adequate amount of keratinized gingiva around the tooth, 2 cases (14\%) due to 
inadequate surgery and 3 cases (22\%) due to the fracture of the tooth structure (Table 1 ).

Comparison of the reasons for failure at 2and 6-week postoperative intervals showed that:

- At the 2-week interval, 7 cases failed due to the absence of adequate keratinized gingiva around the tooth in question, with the same number of failures at the 6 -week interval.

- At the 2-week interval, 3 cases failed due to the presence of granulation tissue around the tooth in question and all such cases exhibited recovery at the 6-week interval.

- At the 2-week interval, there was one failure due to the fracture of the tooth structure after surgery and 2 other cases were added to this kind of failure at the 6-week interval and there were a total of 3 failures due to this reason at the 6-week interval.

\begin{tabular}{|c|c|c|c|c|}
\hline \multirow[b]{2}{*}{ Reason } & \multicolumn{2}{|c|}{2 weeks } & \multicolumn{2}{|c|}{6 weeks } \\
\hline & \multicolumn{4}{|c|}{ No. Percentage No. Percentage } \\
\hline $\begin{array}{l}\text { Coronal returning of the gingival tissue on the tooth } \\
\text { structure }\end{array}$ & 0 & 0 & 2 & 14 \\
\hline Absence of adequate keratinized gingiva around the tooth & 7 & 54 & 7 & 50 \\
\hline Presence of granulation tissue around the tooth & 3 & 23 & 0 & 0 \\
\hline Inadequate surgery & 2 & 15 & 2 & 14 \\
\hline Fracture of the tooth structure after surgery & 1 & 8 & 3 & 22 \\
\hline Total & 13 & 100 & 14 & 100 \\
\hline
\end{tabular}

Table 1: The frequencies of different reasons for the early failures of crown lengthening procedures after 2 and 6 weeks

\section{Discussion}

Crown lengthening surgical procedure is a resective surgery in which a part of periodontal tissues are removed by surgery and the clinician removes a part of the soft tissue or places it at a more apical position. In addition,
- At the 2-week interval, there was no failure due to the coronal returning of the gingival tissue on the tooth structure; however 2 cases of such failure were added to the whole number of failures due to this reason at the 6 week interval.

- At the 2-week interval, 2 cases failed due to inadequate surgery (not creating an adequate distance between the healthy margin and the crest), with no changes in the number of such failures at the 6 -week interval.

- Based on the results, the most common reason for early failure of crown lengthening surgical procedure at both postoperative intervals (second and sixth weeks) was the absence of adequate keratinized gingiva around the tooth in question. important role in the final tissue healing and the treatment outcomes. When there is osseous deformity, removal of bone and the more apical position of the flap have dual advantages of decreasing the probing depth 
and the exposure of the tooth for restoration procedures $(16,17)$.

The treatment failures can be divided into early (before placement of restorations) and late or delayed (after restorative procedures) failures $(14,15)$. The present study evaluated the reasons for early failures and the frequency of each reason at 2- and 6-week postoperative intervals. The results showed a failure rate of $14.5 \%$ for early failures 6 weeks after the crown lengthening procedure for the following reasons: absence of adequate amounts of keratinized gingiva (the most common reason) (50\%), inadequate surgery (not creating an adequate distance between the healthy margin and the crest) (14\%), fracture or removal of the tooth structure after surgery (22\%) and the coronal returning of gingival tissue on the tooth structure (14\%). Based on a study by Pontoriero et al, from the sixth week to the sixth month of healing, $12 \%$ of the subjects exhibited a gingival recession of $2 \mathrm{~mm}$ or higher, indicating the need for regular examination and follow-up of such patients during the healing period up to 6 months after crown lengthening procedures (13).

In addition, the results of the present study showed the presence of granulation tissue around the tooth in question in 3 patients only in the second week. Evaluation of these 3 patients at the 6-week interval showed that in two patients the granulation tissues exhibited themselves in the form of coronal returning of the gingival tissue on the tooth structure and in the third patient gingival tissue recession was evident, which is favorable.

A study by Lanning et al evaluated the success of crown lengthening procedures and re-establishment of the biologic width and showed that $90 \%$ of the areas treated required osteotomy of $3 \mathrm{~mm}$ or higher (6). In addition, in these patients, no significant changes were induced in the vertical position of the free gingival margin during a 3-6-month period (6).
Bragger et al, too, showed that during a 6month healing period after crown lengthening procedure the periodontal tissues exhibited the least changes in the gingival margin levels and remained constant and stable (18).

In this study, the amount of bone resorption was not evaluated after crown lengthening procedures; however, the means of bone resorption during the recovery period after crown lengthening surgery has been reported to range from 0.14 to $0.77 \mathrm{~mm}$ in different studies $(6,19)$.

In the present study, no coronal returning of the gingival tissue on tooth structure was observed at the 2-week interval; however, at the 6-week interval, there were 2 cases (14\%) of such a problem. At longer follow-up periods, repositioning of $3.22 \mathrm{~mm}$ of the supra-crestal gingival tissue in the interproximal area has been reported after two months (19). Pontoriero et al reported a re-growth of 3.2 $\mathrm{mm}$ of the supra-crestal gingival tissue 6 months after restoration (13); Perez et al reported $3.12 \mathrm{~mm}$ of gingival tissue re-growth 12 months after restoration (20).

A study evaluated the success of bone surgery to increase the crown length at 1-, 3and 6-month intervals and reported that the tissue created after crown lengthening procedures does not remain stable after 6 months; rather, it seems the amount of the created tissue depends on the location of the flap margin relative to the crest of the alveolar bone, i.e. the closer the location of the flap suture to the crest of the bone, the greater the amount of the created tissue (21). Arora et al evaluated changes in the level of the periodontal tissue 6 months after crown lengthening procedure and also evaluated factors affecting the stability of the lengthened root; they reported that the achieved crown length during surgery decreased significantly 6 months postoperatively (22). 
Such discrepancies in the results might be attributed to the surgical techniques used, the position of the flap margin relative to the alveolar crest in particular, and the difference in the amount of the crestal bone removed during surgery. It appears the dimensions of the biologic width do not change over time in the presence of good oral hygiene and absence of gingival inflammation (19).

In a prospective study in 2004, Han et al evaluated the outcomes of crown lengthening procedures and factors affecting their success. Based on the results, factors such as anatomical complexities and occlusal forces limit the success of such surgeries and are not proper indications for crown lengthening procedures (23). Diniz et al evaluated the standard bitewing radiographs before and after bone resection at 2-, 3- 6- and 12-month intervals during the healing period of crown lengthening procedures and reported that intact lamina dura at both distal and mesial alveolar crests was visible only after the third month. In addition, at 12-month interval all the alveolar crests exhibited intact lamina dura (24).

In the present study, too, failures of crown lengthening procedures were attributed in $14 \%$ of the cases to the coronal returning of the gingival tissue on the tooth structure and inadequate surgery at the 6-week postoperative interval, indicating the necessity of accurate and regular examinations and follow-ups after crown lengthening procedures.

In approximately $12 \%$ of patients, up to 2 $\mathrm{mm}$ of gingival margin resorption occurs between 6 weeks and 6 months after surgery, which should be taken into account when placing a restoration (18). In addition, the results of the majority of studies show that a certain length of time is necessary for the stabilization of the height of the gingival tissue and this length of time is different in different individuals (13). In addition, the thickness and the width of the gingiva, too, should be taken into account because gingival biotypes with greater thickness and width undergo less resorption (25). In thin biotypes of the periodontium, horizontal bone loss occurs more rapidly and if the area is not cleaned properly, inflammation and pocket formation will be expected; however, in the thick biotype, gingival recession is rare and bone resorption occurs more slowly $(3,25)$.

Some of the limitations of the present study were the irregular attendance of the subjects at the predetermined times for follow-up evaluations after crown lengthening procedures to determine the outcomes of treatment and the impossibility of carrying out the study with a larger sample size due to the limited number of patients requiring crown lengthening procedures in our faculty. In addition, despite the fact that all the surgical procedures were carried out by one surgeon, the impossibility of matching all the surgical conditions and the patient-related factors might have affected the outcomes.

\section{Conclusion}

It can be concluded from the results of the present study that at 6 -week postoperative interval $14.5 \%$ of crown lengthening procedures exhibited early failure and the most frequent reason for the early failure of crown lengthening procedures at 2- and 6-week postoperative intervals was the absence of sufficient keratinized gingiva around the tooth in question. 


\section{References}

1. Bader JD, Rozier RG, McFall WT, Ramsey DL. Effect of crown margins on periodontal conditions in regularly attending patients. The Journal of prosthetic dentistry. 1991;65(1):75-9.

2. Bader J, Rozier R, McFall W. The effect of crown receipt on measures of gingival status. Journal of dental research. 1991;70(10):1386-9.

3. Carranza FA, Newman MG, Takei H, Klekkevold PR. The periodontal pocket. Clinical Periodontology, 10th ed Philadelphia: Saunders/Elsevier. 2006:881-91,15-20.

4. Orkin D, Reddy J, Bradshaw D. The relationship of the position of crown margins to gingival health. The Journal of prosthetic dentistry. 1987;57(4):421-4.

5. Block P. Restorative margins and periodontal health: a new look at an old perspective. The Journal of prosthetic dentistry. 1987;57(6):683-9.

6. Lanning SK, Waldrop TC, Gunsolley JC, Maynard JG. Surgical crown lengthening: evaluation of the biological width. Journal of periodontology. 2003;74(4):468-74.

7. Nevins $M$, Skurow $H$. The intracrevicular restorative margin, the biologic width, and the maintenance of the gingival margin. The International journal of periodontics \& restorative dentistry. 1984;4(3):30.

8. Minsk L. Esthetic crown lengthening. Compendium of continuing education in dentistry (Jamesburg, NJ: 1995). 2001;22(7):562

9. Studer S, Zellweger U, Schärer P. The aesthetic guidelines of the mucogingival complex for fixed prosthodontics. Practical periodontics and aesthetic dentistry: PPAD. 1996;8(4):333-41; quiz 42.

10. Gargiulo AW, Wentz FM, Orban B. Dimensions and relations of the dentogingival junction in humans. Journal of Periodontology. 1961;32(3):261-7.

11. Kois J. " The gingiva is red around my crowns"--a differential diagnosis. Dental economics-oral hygiene. 1993;83(4):101-2.

12. Parma-Benfenali S, Fugazzoto $P$, Ruben $M$. The effect of restorative margins on the postsurgical development and nature of the periodontium. Part I. The International journal of periodontics \& restorative dentistry. 1984;5(6):30-51.

13. Pontoriero R, Carnevale G. Surgical crown lengthening: a 12-month clinical wound healing study. Journal of Periodontology. 2001;72(7):841-8.

14. Smith DH, Ammons Jr WF, Van Belle G. A Longitudinal Study of Peridontal Status Comparing Osseous Recontouring With Flap Curettage: I. Results After 6 Months. Journal of periodontology. 1980;51(7):367-75.

15. Oakley E, Rhyu I-C, Karatzas S, Gandini-Santiago L, Nevins M, Caton J. Formation of the biologic width following crown lengthening in nonhuman primates. The International journal of periodontics \& restorative dentistry. 1999;19(6):529-41.

16. Hempton TJ, Dominici JT. Contemporary crown-lengthening therapy: a review. The Journal of the American Dental Association. 2010;141(6):647-55.

17. Wilderman MN, Pennel BM, King K, Barron JM. Histogenesis of repair following osseous surgery. Journal of periodontology. 1970;41(10):551-65.

18. Brägger U, Lauchenauer $D$, Lang $N$. Surgical lengthening of the clinical crown. Journal of clinical periodontology. 1992;19(1):58-63.

19. Ayubian N. Evaluation of dimensional changes of supraosseous gingiva following crown lengthening. Journal of Periodontology \& Implant Dentistry. 2011;2(2):61-5.

20. Pérez JR, Smukler H, Nunn ME. Clinical evaluation of the supraosseous gingivae before and after crown lengthening. Journal of periodontology. 2007;78(6):1023-30.

21. Deas DE, Moritz AJ, McDonnell HT, Powell CA, Mealey BL. Osseous surgery for crown lengthening: a 6-month clinical study. Journal of periodontology. 2004;75(9):1288-94. 
22. Arora R, Narula SC, Sharma RK, Tewari S. Evaluation of supracrestal gingival tissue after surgical crown lengthening: a 6-month clinical study. Journal of periodontology. 2013;84(7):934-40.

23. Han $W$, Ouyang $X$, Wang $X$. [Prospective study on results of the surgical crown lengthening and its associated factors]. Zhonghua kou qiang yi xue za zhi= Zhonghua kouqiang yixue zazhi= Chinese journal of stomatology. 2004;39(4):280-3.

24. Diniz DE, Okuda KM, Fonseca CR, Gonzalez MKS, Greghi SLA, Valle ALd, et al. Surgical crown lengthening: a 12 month study-radiographic results. Journal of Applied Oral Science. 2007;15(4):280-4.

25. Müller H-P, Eger T. Masticatory mucosa and periodontal phenotype: a review. The International journal of periodontics \& restorative dentistry. 2002;22(2):172-83. 